\title{
Confronto do Uso e Ocupação da Terra em APPs no Município de Muqui, ES
}

Taís Rizzo Moreira ${ }^{1}$, Alexandre Rosa dos Santos ${ }^{2}$, Raphael Lima Dalfi, Rafael Ferraço de Campos ${ }^{1}$, Gleissy Mary Amaral Dino Alves dos Santos ${ }^{3}$, Fernando Coelho Eugenio ${ }^{4}$

\footnotetext{
${ }^{1}$ Departamento de Ciências Florestais e da Madeira, Centro de Ciências Agrárias - CCA, Universidade Federal do Espírito Santo - UFES, Jerônimo Monteiro/ES, Brasil

${ }^{2}$ Departamento de Engenharia Rural, Centro de Ciências Agrárias - CCA, Universidade Federal do Espírito Santo - UFES, Alegre/ES, Brasil

${ }^{3}$ Programa de Pós-graduação em Agroquímica, Universidade Federal de Viçosa - UFV, Viçosa/MG, Brasil ${ }^{4}$ Programa de Pós-graduação em Ciências Florestais, Centro de Ciências Agrárias - CCA, Universidade Federal do Espírito Santo - UFES, Jerônimo Monteiro/ES, Brasil
}

\section{RESUMO}

Para garantir a qualidade de vida da população e a manutenção dos recursos naturais no município de Muqui, localizado no extremo sul do estado do Espírito Santo, Brasil, entre as latitudes 2050' e $21^{\circ} 01^{\prime}$ Sul e longitudes $41^{\circ} 12^{\prime}$ e $41^{\circ} 28^{\prime}$ Oeste de Greewinch, com área de $327,75 \mathrm{~km}^{2}$, foi proposto um estudo a partir de análise utilizando geotecnologias, o qual teve por objetivos delimitar as Áreas de Preservação considerando a legislação ambiental que vigora no município, identificar o uso e ocupação da terra e analisar as áreas de confronto para verificar o grau de degradação, ressaltando a importância de identificarem-se as áreas visando implantar projetos ambientais que promovam ações em busca de um relacionamento sustentável entre homem e ambiente de forma mais eficiente.

Palavras-chave: geotecnologia, recursos naturais, legislação ambiental.

\section{Land Use and Occupation Analysis of Permanent Preservation Areas in the Municipality of Muqui, Espirito Santo State, Brazil}

\begin{abstract}
A study based on geotechnology was carried out to ensure the quality of life and preservation of natural resources in the municipality of Muqui, comprising an area of $327.75 \mathrm{~km}^{2}$, located in

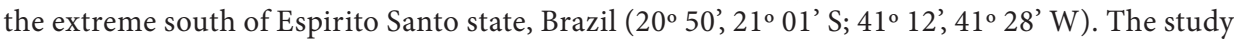
aimed to define Permanent Preservation Areas (PPA) from the viewpoint of the environmental legislation in force in the municipality; classify land use and occupation; identify and analyze conflict areas; and verify the state of degradation, highlighting the importance of identifying areas in order to automatically deploy projects that could efficiently promote environmental actions in pursuit of a sustainable relationship between humans and the environment.
\end{abstract}

Keywords: geotechnology, natural resources, environmental legislation. 


\section{INTRODUÇÃO}

As Áreas de Preservação Permanentes (APPs) são fundamentais para a manutenção da vegetação nativa de determinadas regióes com o objetivo de manter equilibrado o uso da terra, que deve estar coberta pela vegetação original. As APPs atualmente estão submetidas a grandes extensões de degradação devido à intensificação das pressões antrópicas sobre o ambiente, dessa forma observa-se um processo de substituição das paisagens naturais por outros usos e ocupações da terra e a conversão das áreas com cobertura florestal em fragmentos florestais, comprometendo o meio ambiente e, em muitos casos, afetando a disponibilidade de recursos naturais importantes à vida (Espírito Santo, 2006). Devido à dimensão continental de países como o Brasil torna-se indispensável a representação e caracterização das APPs em mapas regionais, sendo importante para o planejamento territorial, na fiscalização e nas ações de campo de âmbito local, regional ou nacional.

O uso da terra, nele incluído o tipo de vegetação e as atividades antropogênicas, afeta a produção de água. Esse fator é dos mais relevantes a ser considerado no manejo de bacias hidrográficas pois, dependendo do tipo de vegetação e das práticas exercidas pelo homem, a produção de água pode ser alterada de forma favorável ou prejudicial aos usuários da bacia (Cicco \& Fujieta, 1992). Perante a forma extremamente dinâmica com que as inúmeras transformações ocorrem no espaço geográfico, a utilização de novas tecnologias para adquirir informações é de extrema importância, por consequência, o uso de geotecnologias é imprescindível para se compreender e analisar a organização do espaço geográfico, otimizando o período hábil de fiscalização e o cumprimento da legislação vigente.

A Geotecnologia adequa-se perfeitamente à abordagem territorial na medida em que permite a distribuição espacial dos dados, a visualização das relações espaciais, a detecção de processos de concentração e de dispersão de fluxos e contrafluxos, bem como a identificação dos processos históricos de comportamento dos dados (Pina, 2009 apud Louzada et al., 2009).

Com a facilidade de acesso a um número cada vez maior de informações provenientes da Geotecnologia, a utilização de novos sensores, com melhor resolução espacial, temporal, radiométrica e espectral, tem se mostrado muito importante para o melhor entendimento dos processos ecológicos e antrópicos que agem nos sistemas terrestres. Em relação ao uso da terra e da cobertura vegetal, essas técnicas contribuem de modo expressivo para a eficiência e confiabilidade nas análises que envolvem os processos de degradação da vegetação natural, podendo assim auxiliar na fiscalização dos recursos florestais e no desenvolvimento de políticas que visem à conservação (Louzada, 2008).

A análise do conflito do uso da terra atrelado ao planejamento e gestão visa compreender a dinâmica da região e estabelecer diretrizes de ocupação que garantam a qualidade de vida da população e a manutenção dos recursos naturais de forma sustentável.

Na elaboração do presente trabalho estipularam-se os seguintes objetivos: delimitar as Áreas de Preservação considerando a legislação ambiental que vigora no município, identificar o uso e ocupação da terra e analisar as áreas de confronto para verificar o grau de degradação, ressaltando a importância de identificaremse as áreas visando implantar projetos ambientais que promovam ações em busca de um relacionamento sustentável entre homem e ambiente de forma mais eficiente.

A delimitação das APPs da rede de drenagem do município juntamente com a delimitação do uso da terra proporcionará a identificação, por meio do confrontamento entre os mapas, das áreas em conflitos com o Código Florestal Brasileiro (Brasil, 2012).

\section{MATERIAL E MÉTODOS}

A área de estudo localiza-se no município de Muqui, extremo sul do estado do Espírito Santo, Brasil, abrangendo as coordenadas geográficas, latitudes $20^{\circ} 50^{\prime}$ e $21^{\circ} 01^{\prime}$ Sul e longitudes $41^{\circ} 12^{\prime}$ e $41^{\circ} 28^{\prime}$ Oeste de Greewinch, com uma área de $327,75 \mathrm{~km}^{2}$.

O clima da região, segundo a classificação de Köppen, é Cwa, caracterizando-se por inverno seco e verão chuvoso. A topografia possui relevo bastante acidentado, intercalado por áreas planas. Basicamente estão estabelecidas na área culturas de subsistência, café e, predominantemente, pastagens, além dos remanescentes florestais nativos localizados principalmente nos topos dos morros.

A base de dados espaciais, informações cartográficas, necessária para a geração do presente estudo foi fornecida 
pelo Sistema Integrado de Bases Georreferenciadas do Estado do Espírito Santo - Geobases, envolvendo banco de dados e uma base cartográfica digital sendo os seguintes planos de informação utilizados no formato "shapefiles" (.shp) (ArcGis/ArcInfo): curva de nível de 20 m; hidrografia; localidades; municípios.

Por meio do Iema foram obtidas aerofotos digitais ortorretificadas na escala 1:35.000, de junho de 2007, sobre a região sul, sendo elas utilizadas para o mapeamento do uso e ocupação da terra.

De posse dessas informações, deu-se início ao trabalho de montagem do mosaico das aerofotos, com o intuito de gerar uma única imagem representativa da área de estudo.

Para a elaboração do Modelo Digital de Elevação Hidrologicamente Consistente (MDEHC) foram utilizados dados vetoriais de curvas de nível com equidistância de 20 em 20 metros (Geobases) com escala de 1:50.000, representativas da área em estudo.

De posse dos referidos dados, a geração do MDHEC para o município de Muqui, foi realizada utilizando-se o algoritmo de interpolação "topo to raster", disponível no módulo Arc Toolbox do programa ArcGIS 10.0. As operações necessárias para geração do MDHEC por meio desse algoritmo exigiram a orientação dos arcos da rede hidrográfica no sentido do escoamento e o ajuste da altimetria à hidrografia.

Em seguida foram realizadas operações de pós-processamento, com a finalidade de identificar e eliminar a ocorrência de imperfeições (depressões espúrias) no MDHEC e para criação de uma calha ao longo da rede hidrográfica, objetivando garantir a convergência do escoamento superficial até a foz da hidrografia. De acordo com Tribe (1992), essas imperfeições são muito frequentes nos MDEHC e derivam de erros presentes nos dados de entrada ou introduzidos no processo de interpolação. As falsas depressões constituem um problema importante na geração de modelos de predição do escoamento, pois interrompem o escoamento superficial. Devem, portanto, ser removidas para se ter um MDE consistente sob o ponto de vista hidrológico. Para o preenchimento dessas imperfeições utilizou-se o comando "fill", disponível no módulo Arc Toolbox do programa ArcGIS 10.0.

Os procedimentos adotados para a classificação do uso e ocupação da terra na região em estudo dividiram-se em quatro etapas: aquisição dos materiais e informações, definição da legenda da fotointerpretação, levantamento dos dados de campo e geração do mapa de uso e ocupação da terra.

O primeiro passo foi a realização da visita de campo, a fim de se verificar in situ a área de estudo, por meio de pontos coletados com aparelho GPS Garmin 12XL, possibilitando confecção da legenda para determinar os padrões para a interpretação das classes de uso da terra.

Na geração do mapa de uso da terra levou-se em consideração a legenda, ou seja, as classes de uso da terra para composição dos mapas, sendo elas obtidas a partir da interpretação visual por meio de técnicas de fotointerpretação da aerofoto e também por intermédio da inspeção de campo.

Temba (2000) descreve alguns fatores importantes para o processo de fotointerpretação, imprescindíveis para uma boa fotoanálise. São eles: forma, tamanho, padrão, textura e tonalidade.

Após estudo desses fatores de interpretação foi possível identificar as classes de uso da terra que compõem a legenda. As classes foram:

- Afloramento rochoso: Local onde ocorre exposição superficial da rocha;

- Árvores: Formação arbórea encontrada isoladamente no perímetro urbano da cidade;

- Área edificada: Áreas ocupadas por construções rurais, com área igual ou maior que a resolução espacial das imagens empregadas;

- Área cultivada: Consideradas áreas de plantio de várias culturas;

- Área degradada: Áreas exploradas pela mineração de mármore e granito;

- Área urbana: Áreas ocupadas por construções em padrão urbano com área igual ou maior que a resolução espacial das imagens empregadas;

- Café: Vegetação arbórea apresentando uma linha de cultivo de porte intermediário;

- Cursos d'água: Córregos, ribeirões e rios;

- Fragmento florestal: Consideradas áreas com vegetação intensa;

- Pastagem: Formação não arbórea, coberta por gramíneas, também utilizadas pela pecuária, contudo sem uso definido;

- Reflorestamento: Áreas ocupadas com plantio de Eucalyptus ou Pinus;

- Reservatório: Área ocupada por água sem movimentação; 
- Solo exposto: Considerado como áreas com solos descobertos e sem a presença de área verde ou construções;

- Várzea: Área de transição entre uma área em declive e um terreno plano, observada pela inclinação da vegetação;

- Vegetação intermediária (campo sujo/capoeira): Áreas que não podem ser consideradas pastagens e nem vegetação arbórea intensa;

- Vegetação rala: Área coberta por gramíneas que se encontram dispostas de forma rala;

- Vias pavimentadas: Estradas com asfalto ou blocos;

- Vias não pavimentadas: Estradas sem calçamento, estradas de chão;

- Voçoroca: Grandes buracos no chão, gerados por erosão.

Para definir as classes do uso da terra consideradas na legenda foi utilizada a classificação visual, gerando-se polígonos em arquivos shapefile, digitalizado-se em tela, em escala 1:1.500, as classes definidas anteriormente, com exceção da classe cursos d'agua, para a qual gerou-se um shapefile do tipo linha. Utilizou-se ainda o shapefile hidrografia do Geobases para localizar mais facilmente esses cursos d'água, mas a escala para fotointerpretação visual permaneceu a mesma, para melhor definição dos padrões em dúvida, realizou-se ampliação da imagem até uma escala de 1:5.000, para verificação e posterior digitalização. Concomitantemente, as informações acerca de quais classes de uso da terra pertencem à zona de exclusão e restrição da área de estudo em questão foram inseridas ao banco de dados do ArcGis 10.0.

Na sequência, as classes fotointerpretadas visualmente em tela foram dissolvidas, proporcionando o seu agrupamento e tornando possível a quantificação da área de cada classe, principalmente em áreas destinadas a APPs, por intermédio da calculadora de valores da tabela de atributos do próprio shapefile. Mesmo sendo um processo mais demorado e trabalhoso, os resultados utilizando-se esse método são confiáveis.

Para avaliar a concordância entre a verdade de campo e o mapa temático obtido pela fotointerpretação utilizou-se a matriz de erro (ou matriz de confusão) e o coeficiente Kappa (Congalton \& Green, 2008). De posse dos processamentos realizados nas etapas anteriores, iniciou-se o mapeamento das APPs considerando-se a faixa marginal dos rios, ao redor das nascentes, nos topos de morros e montanhas (terço superior) e nas encostas com declividade acima de $45^{\circ}$, baseando-se nos critérios estabelecidos pela lei n. 12.651, de 25 de maio de 2012, a qual dispõe sobre parâmetros, definições e limites das APPs (Brasil, 2012).

As APPs ao longo dos cursos d'água (faixa marginal) foram realizadas utilizando-se a base de dados correspondente aos cursos d'água, os quais foram digitalizados em tela sobre as aerofotos ortorretificadas. Utilizou-se o comando "buffer", disponível no módulo Arc Toolbox do programa ArcGIS 10.0, delimitando-se zonas tampões estabelecidas com $30 \mathrm{~m}$ em cada margem, pois no período chuvoso a largura de cada curso d'agua não ultrapassa $10 \mathrm{~m}$.

O mapeamento das APPs ao redor das nascentes foi obtido de forma semelhante à do mapeamento das APPs dos cursos d'água. Essas nascentes foram marcadas manualmente utilizando-se o editor do Arcgis 10.0, embasando-se na hidrografia da região obtida por fotointerpretação. Na delimitação das áreas de preservação no entorno das nascentes executou-se o comando "buffer", disponível no módulo Arc Toolbox do programa ArcGIS 10.0, delimitando-se um raio de preservação de 50 metros no seu entorno.

As APPs de encostas com declividade superior a $45^{\circ}$ ou $100 \%$ foram identificadas a partir da classificação realizada no ArcGIS com as curvas de nível. Foi gerada uma grade de declividade em graus, posteriormente reclassificada, gerando-se um mapa temático em que as áreas cuja declividade apresentava valores iguais ou superiores a $45^{\circ}$ ou $100 \%$ foram consideradas pertencentes a essa classe de APP.

Para a delimitação da APP de topos de morro foi utilizada a metodologia proposta por Hott et al. (2004). Esse método, baseado em geoprocessamento, aplica rigorosamente a legislação e adota um critério na delimitação das elevações por meio do fluxo numérico presente na superfície modelada digitalmente. A identificação e caracterização das elevações por meios numéricos no SIG permitiram a obtenção de informações concernentes aos termos legais e também a padronização dos resultados.

Por meio dos dados obtidos individualmente de cada classe de APP geraram-se mapas que foram agrupados, gerando o mapa de APP. Tais passos podem ser observados no fluxograma da Figura 1. A análise quantitativa das áreas de preservação foi realizada por 


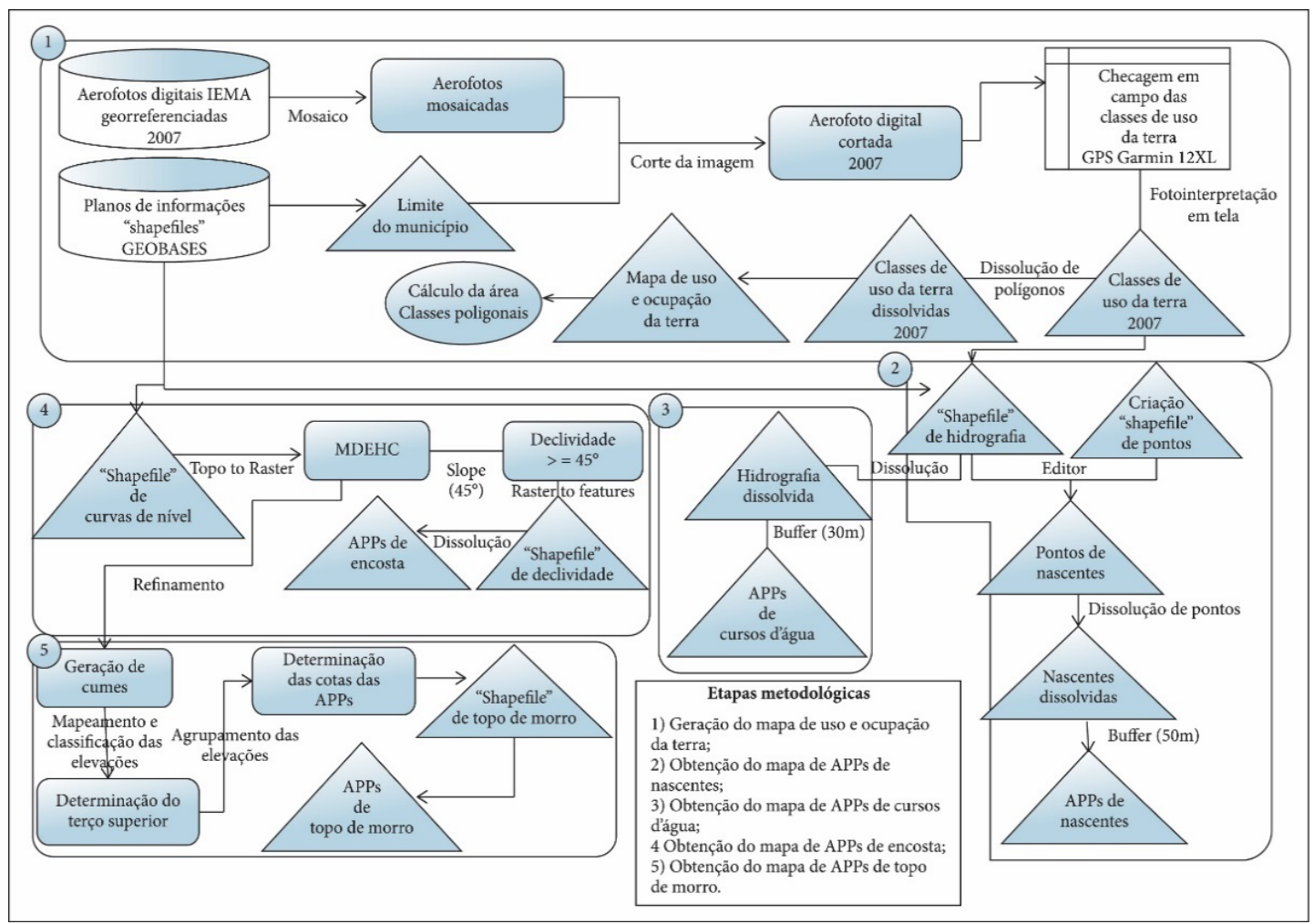

Figura 1. Etapas metodológicas desenvolvidas para obtenção dos mapas de APPs e de uso e ocupação da terra.

Figure 1. Methodological steps undertaken to obtain the maps of APPs and land use and occupation.

meio da comparação direta do valor total encontrado por categorias de APP.

O confronto das áreas foi obtido por meio de cruzamento tabular dos mapas de APPs e de uso da terra, utilizando-se a técnica de sobreposição no ArcGIS 10.0. Assim foi possível quantificar e determinar a porcentagem que cada classe ocupa dentro da área das APPs para todo o município de Muqui.

Dentro da área em estudo foram consideradas sob uso inadequado, conflitante, todas as áreas com pastagem, áreas edificadas, áreas cultivadas, áreas urbanas, com café, campo sujo, capoeira, vegetação rala, voçoroca, vias pavimentadas, vias não pavimentadas, reservatórios, várzeas, solos expostos e áreas degradadas. As áreas ocupadas com vegetação intermediária e fragmentação florestal foram consideradas áreas com uso adequado da terra. Tais considerações foram pertinentes devido ao fato de, em casos nos quais a vegetação nativa foi suprimida dentro da APP, a legislação obrigar o proprietário da área a promover a sua recomposição.

\section{RESULTADOS E DISCUSSÃO}

\subsection{Uso e cobertura da terra}

A imagem obtida através do Iema de junho de 2007 e os levantamentos de campo permitiram identificar e mapear 20 classes de uso da terra, conforme mostrado na Figura 2 e na Tabela 1.

O uso predominante no município é pastagem, com $42,85 \%$ da área em estudo. De acordo com Louzada (2008), essa cobertura vegetal, quando bem cuidada, proporciona o recobrimento da superfície do solo durante todo o ano, reduzindo a velocidade do escorrimento superficial, quando comparado com o de culturas agrícolas, que deixam o terreno exposto durante o preparo do solo para o plantio. No entanto, com as observações de campo notam-se áreas mal manejadas, em parte compactadas, devido à presença de animais, deixando o solo descoberto e sem proteção contra a erosão das chuvas e dos ventos, diminuindo a infiltração e afetando diretamente a vazão das nascentes. 


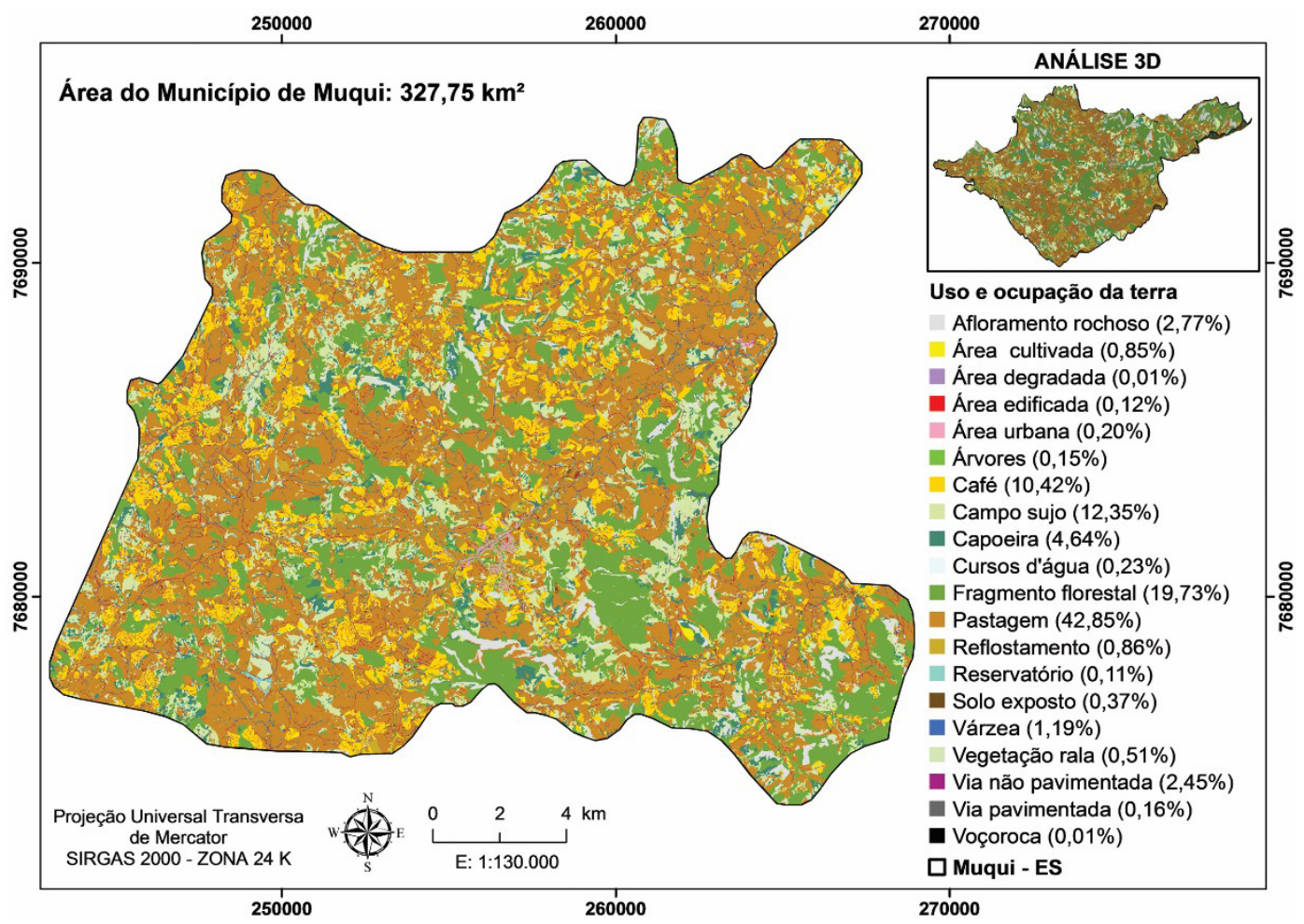

Figura 2. Uso e ocupação da terra para o município de Muqui, ES.

Figure 2. Use and occupation of the land for the city of Muqui, ES.

Tabela 1. Quantificação das classes de uso e ocupação da terra.

Table 1. Quantification of the classes of land use and occupation.

\begin{tabular}{|c|c|c|c|}
\hline Uso da terra & Área $\left(\mathrm{km}^{2}\right)$ & Área (\%) & Perímetro (km) \\
\hline Afloramento rochoso & 9,08 & 2,77 & 503,67 \\
\hline Área cultivada & 2,79 & 0,85 & 196,73 \\
\hline Área degradada & 0,03 & 0,01 & 4,08 \\
\hline Área edificada & 0,41 & 0,12 & 140,92 \\
\hline Área urbana & 0,64 & 0,2 & 97,45 \\
\hline Árvores & 0,5 & 0,15 & 174,2 \\
\hline Café & 34,19 & 10,42 & $1.619,07$ \\
\hline Campo sujo & 40,51 & 12,35 & $2.555,37$ \\
\hline Capoeira & 15,23 & 4,64 & $1.137,62$ \\
\hline Cursos d'água & 0,75 & 0,23 & $1.497,95$ \\
\hline Fragmento florestal & 64,71 & 19,73 & $1.706,01$ \\
\hline Pastagem & 140,28 & 42,85 & $5.354,72$ \\
\hline Reflorestamento & 2,83 & 0,86 & 269,7 \\
\hline Reservatório & 0,37 & 0,11 & 52,05 \\
\hline Solo exposto & 1,22 & 0,37 & 262,45 \\
\hline Várzea & 3,92 & 1,19 & $1.298,49$ \\
\hline Vegetação rala & 1,67 & 0,51 & 138,82 \\
\hline Vias não pavimentadas & 8,03 & 2,45 & $2.527,45$ \\
\hline Vias pavimentadas & 0,54 & 0,16 & 120,67 \\
\hline Voçorocas & 0,04 & 0,01 & 9 \\
\hline Total & 327,75 & 100 & $19.666,41$ \\
\hline
\end{tabular}




\section{2. Áreas de preservação permanente}

As áreas no entorno das nascentes apresentam suma importância no que diz respeito à vida útil dos rios por ela abastecidos, uma vez que sem a proteção adequada em seu entorno nota-se um processo de degradação do rio, o que fora verificado em visitas técnicas à área de estudo, indo ao encontro do verificado por Donadio et al. (2005), que estudaram quatro nascentes, sendo duas com a presença de vegetação natural remanescente e duas com predominância de atividades agrícolas, e concluíram que a presença de remanescentes de vegetação de mata ciliar auxilia na proteção dos recursos hídricos. A área ocupada por essas APPs é de $6,18 \mathrm{~km}^{2}$, o que representa 1,89\% da área total do município (Figura 3).

Devido à natureza do relevo, no município de Muqui ocorre predomínio dos rios de planalto, que apresentam rupturas de declive, vales encaixados, entre outras características que lhes conferem um alto potencial para a geração de energia elétrica. Em decorrência de seu perfil não regularizado, os rios ficam prejudicados no que diz respeito à navegabilidade.

As APPs de curso d'água garantem a estabilização das margens, tendo assim uma importância vital no controle da erosão do solo e da qualidade da água, evitando o carreamento direto para o ambiente aquático de sedimentos, nutrientes e produtos químicos provenientes das partes mais altas do terreno, os quais afetam a qualidade da água, diminuem a vida útil dos reservatórios, das instalações hidroelétricas e dos sistemas de irrigação. A área ocupada pelas APPs de cursos d'água representa $13,44 \%$ de todo o município, totalizando $44,05 \mathrm{~km}^{2}$ (Figura 4).

As APPs de declividade são obtidas nas encostas ou partes delas, com declividade superior a $45^{\circ}$, equivalente a $100 \%$ na linha de maior declive. A área ocupada por essa APP abrange $0,92 \%$ de toda a bacia, totalizando $3 \mathrm{~km}^{2}$ (Figura 5).

Devido ao seu relevo acidentado, essa bacia possui uma extensa área ocupada pelas APPs em topo de morro, áreas importantes de serem protegidas uma vez que são instrumentos de relevante interesse ambiental e

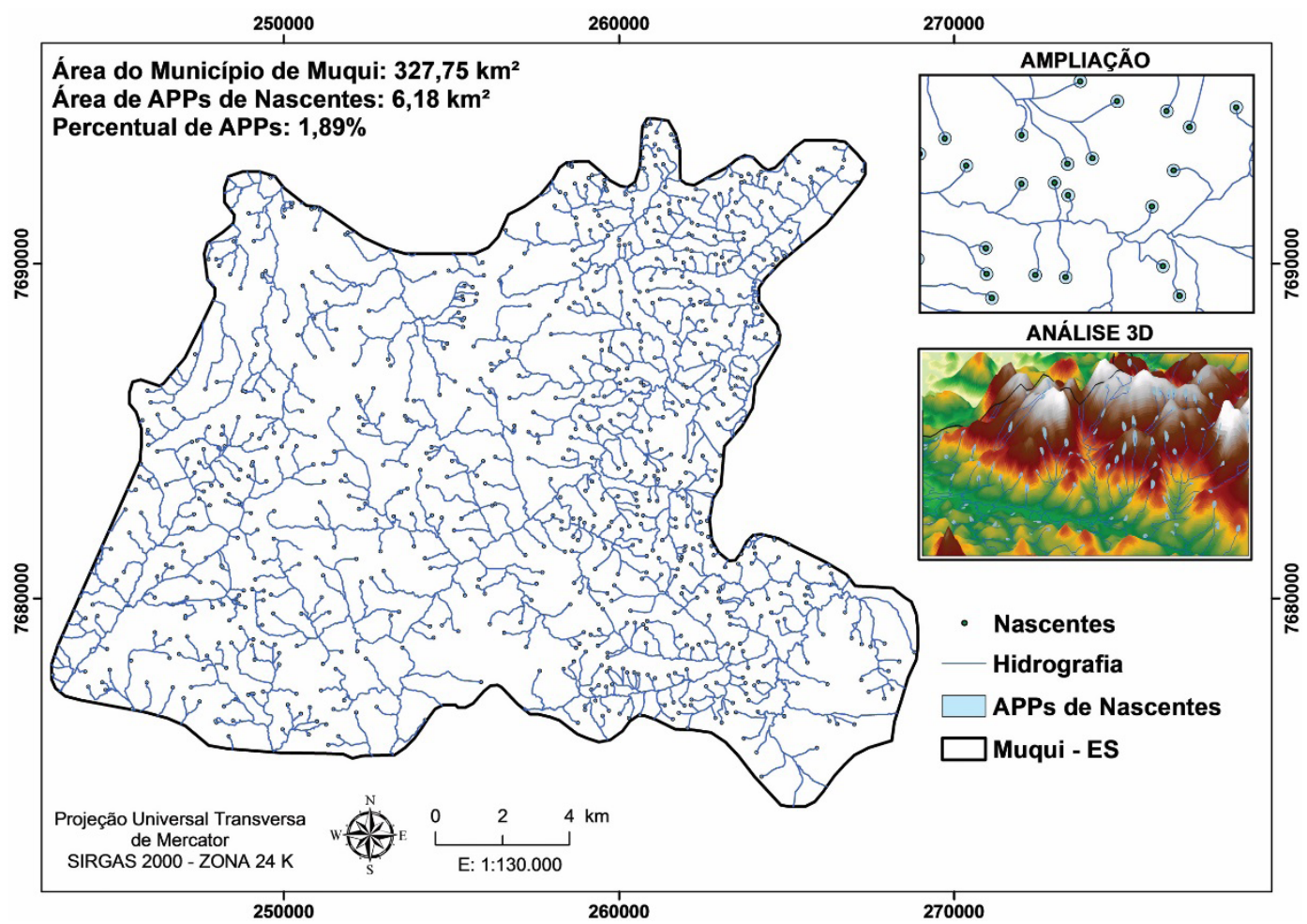

Figura 3. Total das APPs de nascentes do município de Muqui, ES.

Figure 3. Total of the APPs of the municipality of Springs Muqui, ES. 


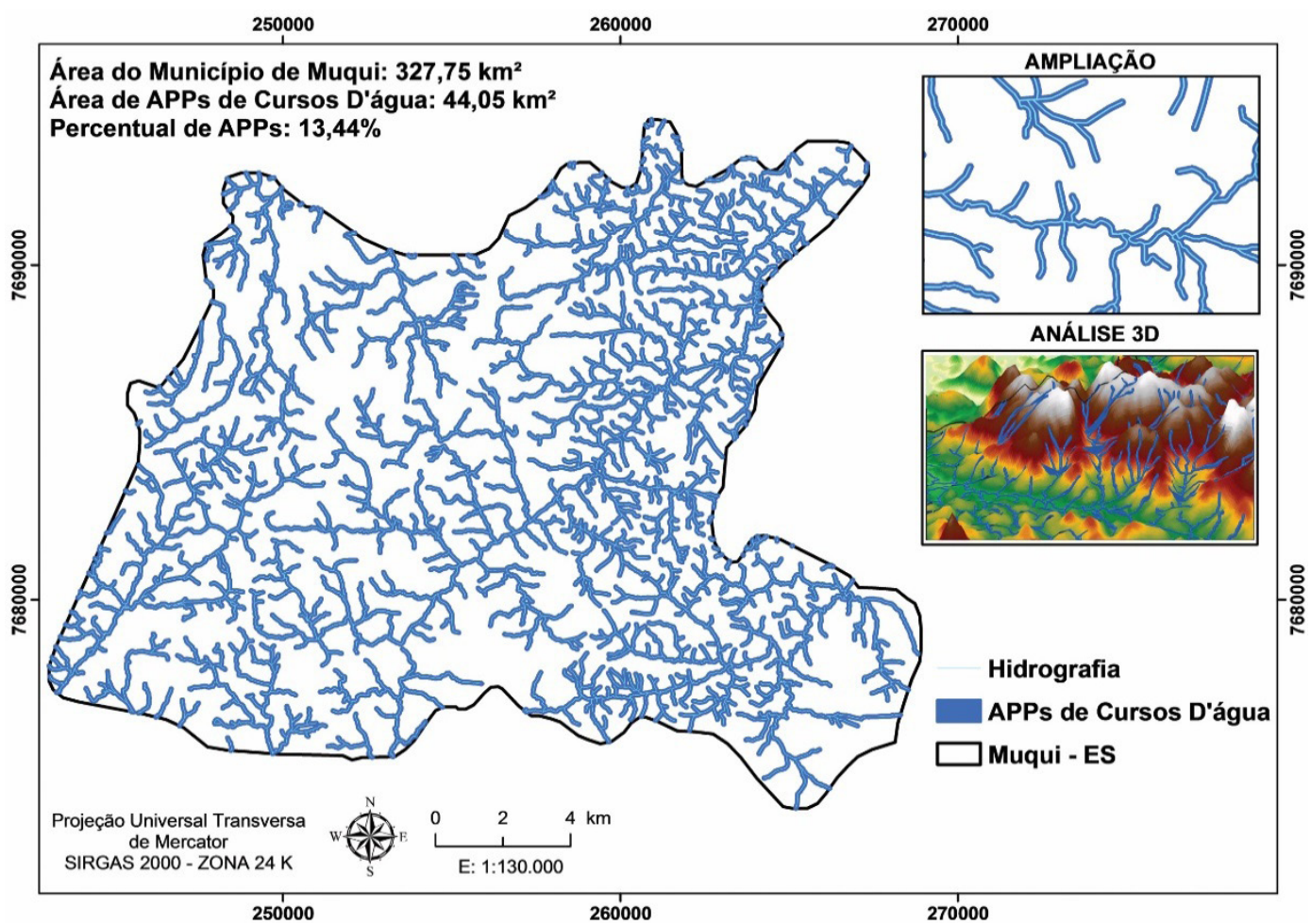

Figura 4. Total das APPs de cursos d'água do município de Muqui, ES.

Figure 4. Total of the APP Water Course in the city of Muqui, ES.

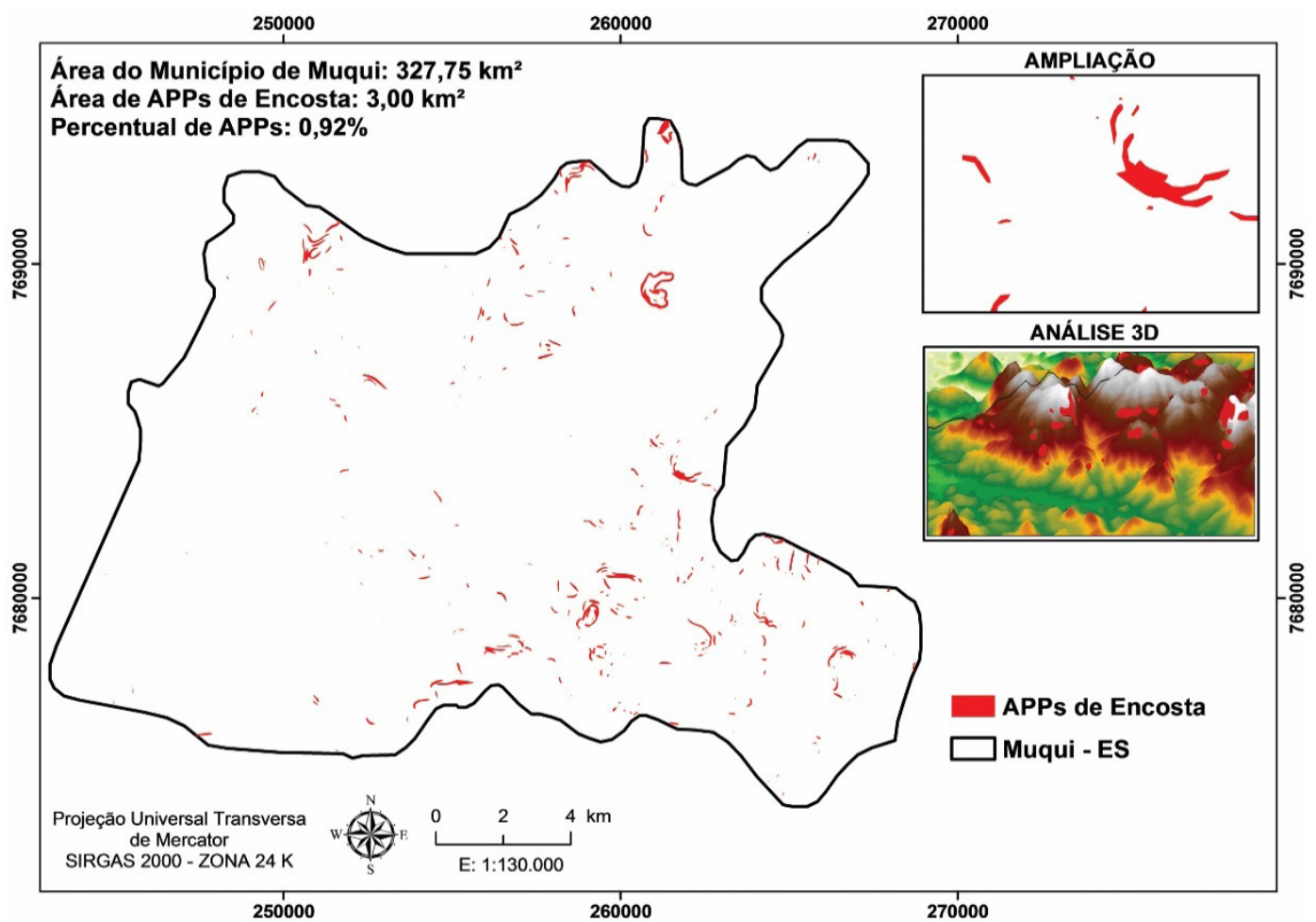

Figura 5. Total das APPs com declive igual ou maior que $45^{\circ}$ do município de Muqui, ES.

Figure 5. Total of the APP slopes of the city of Muqui, ES. 
integram o desenvolvimento sustentável do município, visando gerações futuras. A área ocupada por essas APPs é de $74 \mathrm{~km}^{2}$, o que representa $22,58 \%$ da área total do município (Figura 6).

Nota-se ainda que as APPs ocupam uma área total de $119,5 \mathrm{~km}^{2}$, de um total de $327,75 \mathrm{~km}^{2}$ da área do município, representando $36,46 \%$ de áreas legalmente protegidas (Tabela 2 e Figura 7).

\subsection{Confronto do uso e ocupação da terra em relação às APPs}

Os resultados do confronto das áreas obtido por meio de cruzamento tabular dos mapas de APPs e de uso e cobertura da terra, então dispostos na Figura 8 e na Tabela 3.
Do total da área destinada às APPs, $68,20 \%$ encontrase em uso conflitante da terra, já desconsiderando-se as classes reflorestamento, afloramento rochoso, árvores, cursos d'água e fragmento florestal, uma vez que essas já estão em processo de conservação, sendo necessário, portanto, recompor $81,48 \mathrm{~km}^{2}$ com vegetação nativa. Uma grande área das APPs é degradada devido ao impacto negativo das pastagens, que ocupam $37,37 \%$ da área destinada à proteção ambiental, compactando os solos e contaminando as águas.

Ante os resultados apresentados neste estudo, pode-se recomendar, de acordo com Louzada (2008) e Louzada \& Santos (2009), algumas medidas de controle e prevenção para recuperação das áreas do município de Muqui em confronto com a legislação, tais como a

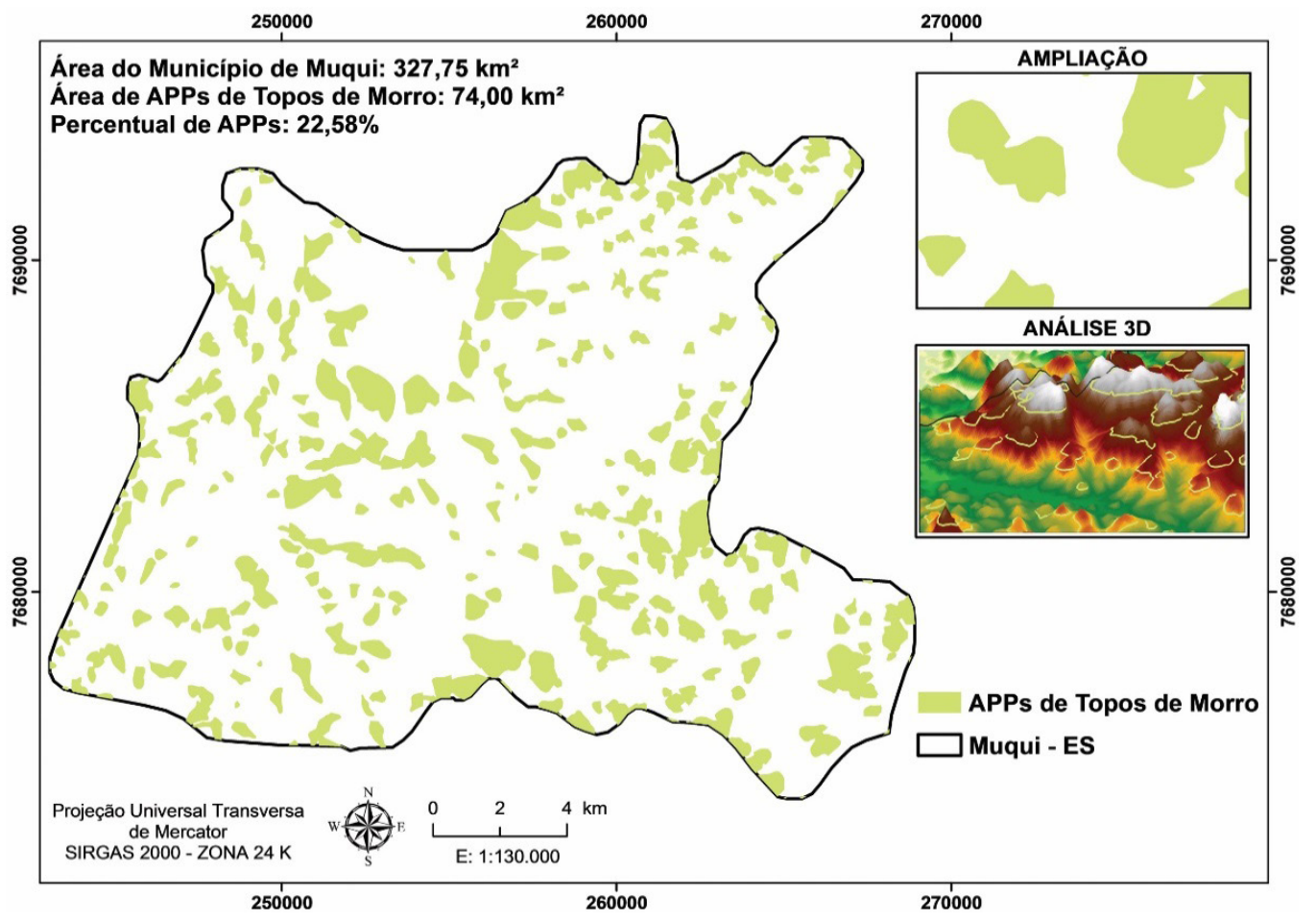

Figura 6. Total das APPs de topo de morro do município de Muqui, ES.

Figure 6. Total of the APPs of the hilltop city of Muqui, ES.

Tabela 2. Porcentagem das áreas ocupadas pelas APPs no município de Muqui, ES.

Table 2. Percentage of areas occupied by the city of APPs Muqui, ES.

\begin{tabular}{cccc} 
APPs & Característica & Área $\left.\mathbf{( k m}^{2}\right)$ & $\begin{array}{c}\text { \% (ocupada na área do } \\
\text { município) }\end{array}$ \\
\hline APP-1 & Raio de $50 \mathrm{~m}$ & 6,18 & 1,89 \\
\hline APP-2 & Buffer de $30 \mathrm{~m}$ & 44,05 & 13,44 \\
\hline APP-3 & Acima de $45^{\circ}$ & 3 & 0,92 \\
APP-4 & Terço superior de morro & 74 & 22,58 \\
\hline Total & Sem sobreposições & 119,5 & 36,46 \\
\hline
\end{tabular}




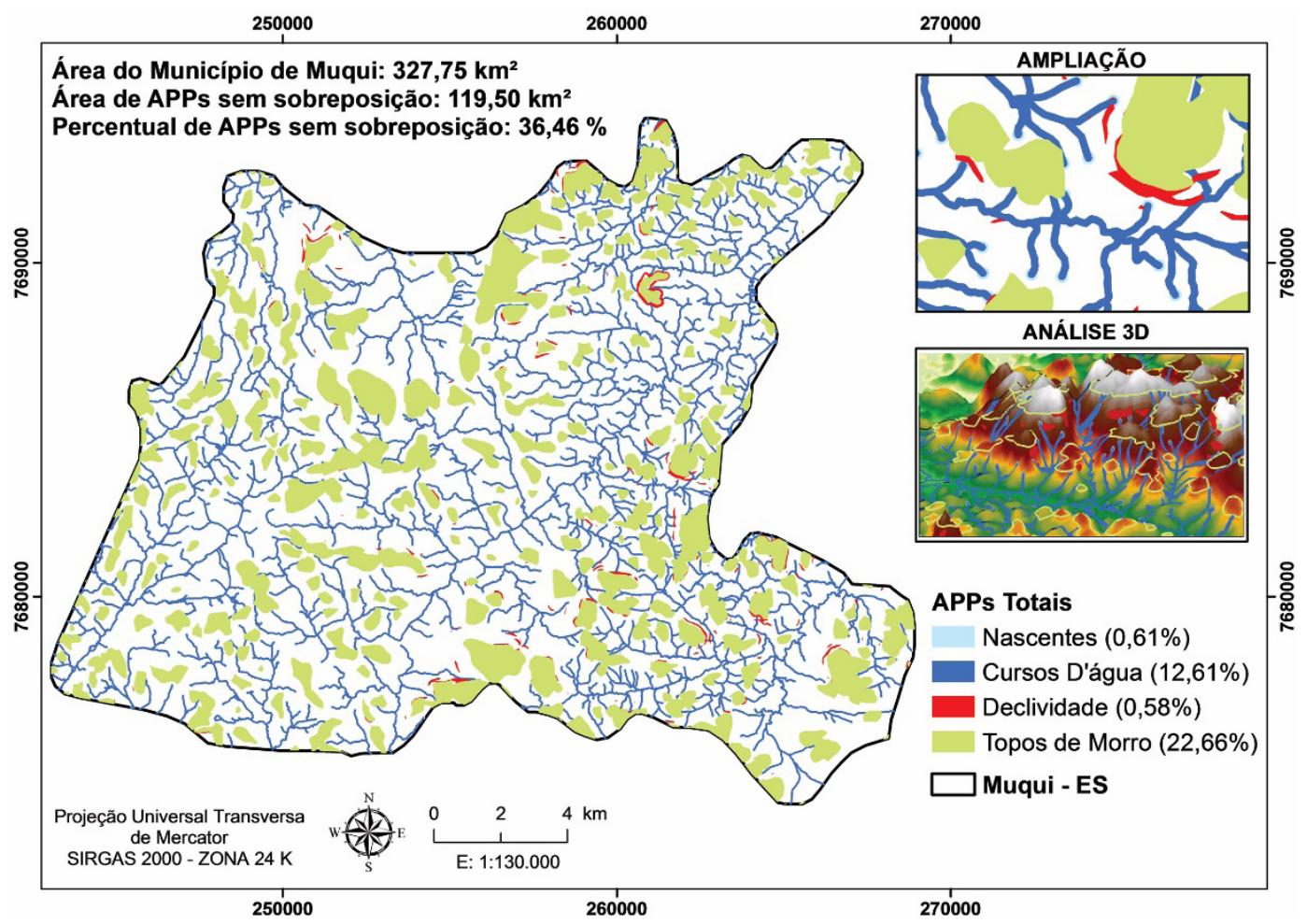

Figura 7. Total das APPs do município de Muqui, ES.

Figure 7. Total of the of the Municipality of APPs Muqui, ES.

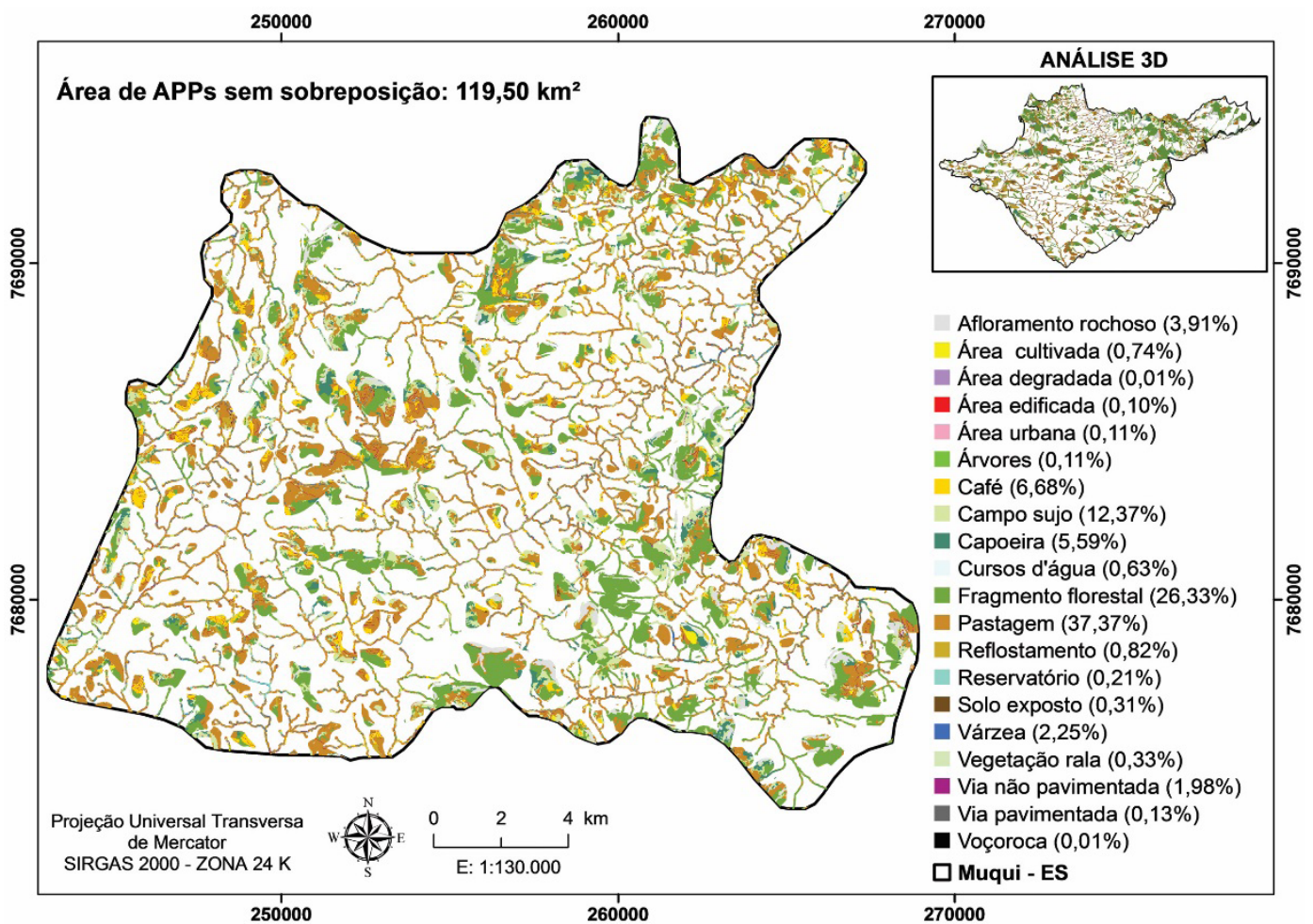

Figura 8. Confronto do uso e ocupação da terra em relação às APPs totais.

Figure 8. Head of Land use in relation to the total APPs. 
Tabela 3. Quantificação das áreas de uso e ocupação da terra nas APPs em Muqui, ES.

Table 3. Quantification of the areas of use and occupation of land in the Muqui, ES.

\begin{tabular}{lcc}
\hline \multicolumn{1}{c}{ Classe de uso da terra } & Área em $\mathbf{~ k m}^{2}$ & $\%$ \\
\hline Afloramento rochoso & 4,67 & 3,91 \\
\hline Área cultivada & 0,88 & 0,74 \\
\hline Área degradada & 0,02 & 0,02 \\
\hline Área edificada & 0,12 & 0,10 \\
\hline Área urbana & 0,13 & 0,11 \\
\hline Árvores & 0,13 & 0,11 \\
\hline Café & 7,98 & 6,68 \\
\hline Campo sujo & 14,78 & 12,37 \\
\hline Capoeira & 6,68 & 5,59 \\
\hline Cursos d'água & 0,75 & 0,63 \\
\hline Fragmento florestal & 31,46 & 26,33 \\
\hline Pastagem & 44,65 & 37,37 \\
\hline Reflorestamento & 0,98 & 0,82 \\
\hline Reservatório & 0,25 & 0,21 \\
\hline Solo exposto & 0,37 & 0,31 \\
\hline Várzea & 2,69 & 2,25 \\
\hline Vegetação rala & 0,39 & 0,33 \\
\hline Vias não pavimentadas & 2,37 & 1,98 \\
\hline Vias pavimentadas & 0,16 & 0,13 \\
\hline Voçorocas & 0,01 & 0,01 \\
\hline Total & 119,5 & 100 \\
\hline & & \\
\hline
\end{tabular}

recuperação vegetal com práticas de reflorestamento, o qual pode ser feito pelo plantio de mudas ou ressemeio, fiscalização mais efetiva dos órgãos ambientais, com o intuito de prevenir e multar os possíveis infratores, e a criação de um sistema que possa fornecer informações relevantes à implantação de projetos de uso e ocupação da terra, proteção e conservação ambiental da região.

\section{CONCLUSÕES}

Nas condições em que os estudos foram conduzidos, a análise dos resultados permitiu apresentar as seguintes conclusões:

A metodologia adotada para delimitação das APPs mostrou-se eficiente, produzindo de forma eficaz e rápida, informações precisas sobre suas dimensões e distribuição espacial no município de Muqui.
Observou-se a falta de preservação e o não cumprimento da legislação referente ao uso da terra em APPs dos cursos d'água, nascentes, topos de morro e encostas;

Necessidade de implantar uma política de educação ambiental junto aos moradores e frequentadores da região, para que juntamente com um plano de recomposição se realizem melhoras nas áreas no que tange a projetos de reflorestamento e conservação dos fragmentos florestais já existentes.

\section{STATUS DA SUBMISSÃO}

Recebido: 7 ago., 2012

Aceito: 24 nov., 2014

\section{AUTOR(ES) PARA CORRESPONDÊNCIA}

\section{Taís Rizzo Moreira}

Departamento de Ciências Florestais e da Madeira, Centro de Ciências Agrárias, Universidade Federal do Espírito Santo - UFES, CEP 29550-000, Jerônimo Monteiro, ES, Brasil e-mail: taisr.moreira@hotmail.com

\section{REFERÊNCIAS}

Brasil. Lei no 12.651 de 25 de maio de 2012. Dispõe sobre a proteção da vegetação nativa; altera as Leis nos 6.938, de 31 de agosto de 1981, 9.393, de 19 de dezembro de 1996, e 11.428, de 22 de dezembro de 2006; revoga as Leis nos 4.771, de 15 de setembro de 1965, e 7.754, de 14 de abril de 1989, e a Medida Provisória no 2.166-67, de 24 de agosto de 2001; e dá outras providências. Diário Oficial da República Federativa do Brasil, Brasília, DF (2012 maio 25).

Cicco V, Fujieta M. Pesquisa de manejo de bacias hidrográficas em São Paulo. Revista do Instituto Florestal 1992; 4(Pt. 3), 808-816. Edição dos Anais do II Congresso Florestal de Essências Nativas. Edição especial.

Congalton RG, Green K. Assessing the accuracy of remotely sensed data: principles and practices. 2. ed. Boca Raton: CRC Press; 2008.

Donadio NMM, Galbiatti JA, Paula RC. Qualidade da água de nascentes com diferentes usos do solo na bacia hidrográfica do córrego Rico, São Paulo, Brasil. Engenharia Agrícola 2005; 25(1): 115-125. http://dx.doi.org/10.1590/ S0100-69162005000100013.

Espírito Santo. ARES: Atlas das áreas com potencial de riscos do Estado do Espírito Santo. Vitória: Imprensa Estadual, 2006. 125 p.

Hott MC, Guimarães M, Miranda EE. Método para a determinação automática de áreas de preservação permanente 
em topos de morros para o Estado de São Paulo, com base em geoprocessamento. Campinas: Embrapa Monitoramento por Satélites; 2004. Documentos n. 34.

Louzada FLRO, Santos AR, Marinho CC, Satler MA. Delimitação automática das áreas de preservação permanentes da bacia hidrográfica do ribeirão Estrela do Norte, ES. In: Anais do IX Encontro Latino Americano de Pós-Graduação- EPG. Ciência e Tecnologia: o paradigma do século XXI; 2009. São José dos Campos. São José dos Campos: UNIVAP; 2009.

Louzada FLRO, Santos AR. Conflito do uso e ocupação do solo em APPs da bacia hidrográfica do ribeirão Estrela do Norte- ES. In: Anais do IX Encontro Latino Americano de Pós-Graduação- EPG. Ciência e Tecnologia: o paradigma do século XXI; 2009. São José dos Campos. São José dos Campos: UNIVAP; 2009.

Louzada FLRO. Análise das áreas de preservação permanente da bacia hidrográfica do ribeirão Estrela do Norte - ES [monografia]. Alegre: Faculdade de Filosofia Ciências e Letras de Alegre; 2008.

Temba P. Fundamentos de fotogrametria [online]. Belo Horizonte: UFMG; 2000. [citado 2008 dez. 23]. Disponível em: http://www.csr.ufmg.br/geoprocessamento/publicacoes/ fotogrametria.pdf

Tribe A. Automated recognition of valley lines and drainage networks from grid digital elevation models: a review and a new method. Journal of Hidrology 1992; 139(1-4): $263-$ 293. http://dx.doi.org/10.1016/0022-1694(92)90206-B. 